\title{
A Syllabi Analysis of Social Media for Teaching and Learning Courses
}

\author{
Enilda Romero-Hall \\ The University of Tampa \\ Linlin $\mathrm{Li}$ \\ The University of Tampa
}

\begin{abstract}
The purpose of this syllabus analysis was to explore the structure of courses focused on social media and geared towards education professionals. Fourteen course syllabi from institutions located within the United States (U.S.) were analyzed as part of this investigation. The results of the analysis revealed a total of 46 unique topic themes across the different courses. The findings show that the most common course objectives aimed to encourage application and practice of social media as part of a learning experience and the learners' professional practice. In total, the syllabi listed 67 unique required readings including: nonpeer reviewed publications, peer-reviewed journal articles, and textbooks. Last, the analysis of the assignments listed in the syllabi show that in these social media courses, there were a mix of traditional and non-traditional assessment methods. These non-traditional assessment methods focused on integrating social media as part of the assessment in which learners were required to create a social media account, become familiar with it, and create learning experiences incorporating a specific social media platform.
\end{abstract}

\section{Introduction}

Once upon a time, we lived in world without social media and social networking sites. Those days are long gone. It is fair to say that in the last two decades our extensive use of social media has changed our lives and the way we communicate with others, receive information, create content, share content with others, and entertain ourselves, among other actions. The use of social media is so widespread that it has even become part of our teaching and learning experiences in K-12 (Becker \& Bishop, 2016), higher education (Evans, 2014), and professional development 
(Greenhalgh \& Koehler, 2017). There are a multitude of cases and research projects in which investigators address how, when, why, and where social media was used as part of a learning experience (Dabbagh \& Kitsantas, 2012; Manca \& Ranieri, 2016, 2017).

There are positive and negative aspects to the use of social media in our daily lives (Hemsley, Jacobson, Gruzd, \& Mai, 2018). Similarly, there are favorable and unfavorable factors when it comes to integrating social media in teaching and learning (Brookfield, 2015; Krutka \& Carpenter, 2017). However, it is imperative that we figure out ways to use these mediums in a promising manner and to educate others on how to foster learning experiences within these environments. This is especially important for education professionals who teach others about innovative and collaborative learning experiences. Teachers, curriculum designers, instructional designers, and learning experience designers ought to learn how to leverage social media as a collaborative learning mechanism.

Today, many graduate and continuing education programs offer courses that focus on the application of social media as a medium to foster collaboration. The aim of this research project is to explore and describe the structure of these courses using a syllabus analysis research method. This type of research methodology can provide information about the core curriculum taught in these courses (Cañadas, Gómez, \& Rico, 2013; Stanny, Gonzalez, \& McGowan, 2015). This research also serves to extract and recognize the tasks and learning opportunities, used in these courses, in a more systematic and direct manner (Cañadas et al., 2013; Stanny et al., 2015). Overall, this research serves to inform future design and development of courses related to the use of social media for teaching and learning.

\section{Review of Related Literature}

\section{Social Media in Higher Education}

Social media has been adopted by institutions of higher education for more than just recruitment and marketing purposes (Benson \& Morgan, 2013; Dabbagh \& Kitsantas, 2012; Manca \& Ranieri, 2016, 2017). The use of social media has been integrated into formal and informal teaching and learning experiences in universities across the globe (Allen \& Nelson, 2013; Bista, 2015; Lin, Hoffman, \& Borengasser, 2013; Alzouebi \& Isakovic, 2014). The success of social media in informal and formal manners in higher education varies tremendously. Yet, we continue to research in hopes that we can better understand how to leverage these social spaces for teaching and learning.

The amount of research related to social media in teaching and learning within higher education is exhaustive (Bista, 2015; DiVall \& Kirwin, 2012; Xi, Hui, de Pablos, Lytras, \& Yongqiang, 2016; Lin, Hoffman, \& Borengasser, 2013). Researchers have focused on understanding: how different platforms can be used in varying learning experiences (Alzouebi \& Isakovic, 2014; Bista, 2015; DiVall \& Kirwin, 2012; Evans, 2014; Tuten \& Marks, 2012), how and when informal learning can occur within these environments (Lin et al., 2013; Tess, 2013), how social media can serve to enhance professional development (Luo, Sickel, \& Cheng, 2017; Romero-Hall, 2017), the types of content and connections that occur when using social media for teaching and learning (Guidry \& Pasquini, 2013), the culture-specific parameters that have an effect on learning experiences with social media communities (Atkins, Koroluk, \& Stranach, 2017), the locations of the knowledge sharing activities (Greenhalgh, Staudt Willet, Rosenberg, \& Koehler, 2018), the learning experiences that field-specific students encounter when using social media (Evans, 2014; Myers, Jeffery, Nimmagadda, Werthman, \& Jordan, 2015; Pham, 2014; 
Spallek et al., 2015) and the tensions and uncertainties that scholars who use social media experience themselves (Kimmons \& Veletsianos, 2016; Veletsianos \& Stewart, 2016), amongst other topics.

In addition to the previously mentioned documented cases and investigations; social media is also a subject taught to undergraduate and graduate students in college. It is not uncommon to see courses related to social media as part of the curriculum of communication, new media, marketing, and other majors. Some of these course titles are Introduction to New Media, Social Media Marketing, Introduction to Social Media Practice, Mobile and Social Media Communication, Social Media and Society, and others (Brocato, White, Bartkus, \& Brocato, 2015). More recently, there have been a number of courses designed and developed, in higher education institutions, with the intent of teaching learners to leverage social media as a collaborative learning mechanism. These courses are intended for education professional who will work in various settings and varying populations.

Although there have been a significant number of investigations related to the use and implementation of social media in higher education (Bista, 2015; DiVall \& Kirwin, 2012; Lin et al., 2013; Xi et al., 2016), only a small number of studies have explored the curriculum of the courses teaching about social media (Brocato, White, Bartkus, \& Brocato, 2015; Faulds \& Mangold, 2014; Gomes, Butera, Chretien, \& Kind, 2017). These investigations have primarily focused on the social media curriculum in non-education related programs. Therefore, due to its newness, research on the curriculum of courses that focus on social media for teaching and learning has not been explored before.

\section{Syllabus Analysis}

To adequately explore the curriculum of courses that focus on social media for teaching and learning, this investigation uses a syllabus analysis approach. Some of the content of a course syllabus is often determined by institutional or departmental policy (e.g., attendance, plagiarism, communication and email, professionalism, etc.); however, instructors write syllabi primarily to describe the organization and detailed content of a course. Key information that is often included in the course syllabus are the topic the instructor intends to cover, the assignments students are expected to complete, and the assessment strategies that will evaluate learning outcomes. As stated by Bers, Davis, and Taylor (2000), outside of direct observation of a classroom, course syllabi are unobtrusive but powerful indicators of what takes place in a course.

Syllabus analysis has been used in the past for various reasons. This research methodology has served to establish the content dimension of curriculum in a culture-specific context (Cañadas et al., 2013), to identify essential language skills that help support second language acquisition instruction (Ji-Yeon, Wooyeon, \& Heewon, 2013), and identify and understand the general characteristics of a program offered by universities in a specific geographical region (Villar et al., 2017). Additionally, as mentioned in the previous section, syllabus analysis has been also used to help determine the curriculum for a specific course topic (Brocato et al., 2015; Faulds \& Mangold, 2014; Gomes et al., 2017). In this investigation, the syllabus analysis research methodology serves to explore the curriculum (topics, content, and assessments) of the courses about social media for teaching and learning. 


\section{Purpose Statement and Research Questions}

The purpose of this syllabus analysis is to explore and describe the structure of courses focused on social media for teaching and learning and geared towards education professionals. This investigation provides information about the core curriculum taught to graduate students in these courses. It also serves to extract and recognize, in a more systematic and direct manner, the tasks and learning opportunities used in these courses to teach learners about social media as a collaborative medium. The aim of this research is to inform future design and development of courses related to the use of social media for teaching and learning and it seeks to answer the following research questions:

RQ1: What are the main objectives of the courses?

RQ2: What content and topics are covered in the courses?

RQ3: How is knowledge conveyed in the courses?

RQ4: How is learning assessed in the courses?

\section{Methods}

\section{Collection of Syllabi}

To investigate current social media curriculum and address our research questions, syllabi from courses geared towards education professional that focused on teaching about "social media for teaching and learning" as a primary topic were collected. The procedures used to collect syllabi were straightforward and mirrored those used in related research (Brocato et al., 2015). The initial step involved inviting instructors who teach courses related to "social media for teaching and learning" in instructional design (educational technology, instructional technology, or learning sciences) graduate programs to submit a copy of their syllabus. Instructors were asked to consent to participate and a link was provided for them to submit their syllabus. Instructors were not required or asked to provide any additional information. The email invitation was sent to all members of the Association of Educational Communications and Technology (AECT), the members of the IT forum listserv, and it was shared via different social media channels used by the researchers.

The final step in the data collection process involved an extensive web search for syllabi that focused on "social media for teaching and learning" geared towards education professionals. The search was restricted to courses taught in the English language. Several keywords were used in the search along with the word "syllabus." These included: social media, instructional design, education, and collaborative learning. Relevant syllabi were accessed and downloaded into a digital folder. Next, the researchers used the Curricular Data of Degree Programs in Educational Technology and Communications posted in the AECT website to visit the webpage of all the programs listed. For each program webpage, the researchers search for course syllabi that could be included as part of this investigation. Any relevant syllabi that were identified were downloaded into a digital folder.

The syllabi collected were pre-evaluated to determine the extent to which they reflected the desired topic of this investigation. Overall, the collection process resulted in a total of fourteen usable course syllabi. The syllabi were from institutions located within the United States (U.S). The courses were described in the syllabi as taught in a variety of formats: online, hybrid, and face-to-face. Some course syllabi did not describe the instructional format. Based on the semester listed in the syllabi, these courses were offered between Fall 2016 and Summer 2018. Some syllabi 
$(n=8)$ did not include the semester the course was offered. Similarly, some syllabi included the instructional level of the learners. Those syllabi with the instructional level listed $(n=6)$ state that the course was offered to master level students.

\section{Content Analysis Procedure}

As a collaborative research team, we employed an iterative, process-oriented team coding approach. Our process consisted of two phases. During the first phase, a spreadsheet was created with columns that represented the content that would be extracted from the syllabi. The columns included in the spreadsheet were the following: name of institution, instructional format of the course, level of instruction (master or doctoral), course number, course title, semester the course was offered, required textbook(s), recommended textbook(s), required reading(s), recommended reading(s), course description, course objectives, course outcomes, topics covered in the course, and types of assignments. Each syllabus was processed. This meant that information was located in each syllabus and added to the spreadsheet for further analysis. If any of the information could not be found in the syllabus, the column was mark "not available (N/A)." We found that extracting this information from the syllabi was useful as an organizational frame because it was often visibly implicit or explicit within the syllabi framework.

During second phase, two researchers conducted a content analysis focused on identifying patterns and clusters across the different syllabi. Content was analyzed focusing on data related to the following clusters: course objectives, topics listed, required textbooks, required readings, and required assignments.

To augment the quality of our analysis we engaged in peer checking during the analysis phase. Further, to enhance the rigor of the study and analysis, we actively engage in a reflexive process in which we constantly located ourselves and our analysis in relation to our own lived experience, positionality, and epistemology. Last, data were checked by a third coder for accuracy and external validity.

\section{Results}

\section{RQ1: What are the main objectives of the courses?}

All course objectives identified in the syllabi were initially open coded. This process helped distinguished the nature of the course objectives. After this initial process, several emerging codes were analyzed and grouped into specific categories. These categories were used to re-code the course objectives listed in the syllabi.

The results revealed that the most common course objectives aimed "to encourage application and practice of social media as part of a learning experience and the learners professional practice" (e.g., "Design a plan to help colleagues incorporate the use of twitter as an educational tool and a collaborative tool"). Other course objectives focused on the learners' ability to: perform a task within a platform (e.g., "Participate in a Twitter Chat and make a record of the important tweets"), evaluate the different social media spaces in terms of learning experiences (e.g., "Analyze the various uses of Twitter in the classroom"), and understand basic social media concepts (e.g., "Identify major social media platforms and the role they play"). A few course objectives appeared to reflect on specific concepts such as ethical use of social media, informal learning in social media communities, the importance of social media in education, and the definition for the term social media (see Table 1). 
These results illustrate an emphasis, within the courses, for practical application of the knowledge acquired through implementation and evaluation. The most common objectives clearly aim to ensure that the learner knows how to concretely incorporate social media collaboratively for learning. Additionally, these results helped established that different courses place various levels of importance on conceptual areas of social media knowledge such as the importance of social media in education, ethics and legal issues, and the definition of social media.

Table 1. Course Objectives

\section{After completing the course, the learner will be able to: Number of Syllabi}

Implement social media as part of a learning experience

Explain social media concepts and applications

Use social media professionally and strategically

Perform social media activities (tweet, post, share, etc.)

Explain the societal implications of social media use

Evaluate social media and its implications to different learning experiences

Discuss the role of social media in the learning process

Discuss the ethical and legal issues related to social media use

Discuss the importance of social media on informal learning

Discuss the importance of social media in education

Define social media

1

\section{RQ2: What content and topics are covered in the courses}

Similar to the analysis of the course objectives, topics identified in the syllabi were open coded. This process helped pinpoint the nature of the topics mentioned. The topics were analyzed and grouped into specific themes. These themes were used to re-code all the topics listed.

The results of the analysis revealed a total of 46 unique topic themes across the different courses. The analysis allowed the researchers to determine which topics were listed in the different syllabi and the frequency in which they were mentioned (see Table 2). Based on the topic themes listed in Table 2, it is obvious that there is a wide range of topics that are covered in these courses. The results seem consistent with the equally immense amount of research related to social media in education; specifically, in higher education. It is likely that instructors are still trying to determine which topics are more relevant to education professionals who wish to learn about social media as a medium for collaborative learning.

Overall, the most frequent topic theme was digital citizenship. This finding appears to connect to the previous results related to the most frequent category of learning objectives, which focuses on adequate and practical ways wherein educational professionals can use social media 
(technology) to create positive and effective digital learning experiences. Another interesting finding related to the topic themes in these course syllabi is the mentioned of Twitter more so than the other social networking platforms (e.g. Facebook, Instagram, Google+, LinkedIn, Pinterest, and YouTube).

Table 2. Course Topics (Themes) Listed in the Syllabi

\begin{tabular}{|c|c|}
\hline Course Topics & $\begin{array}{c}\text { Number of } \\
\text { Syllabi }\end{array}$ \\
\hline Artificial Intelligence & 1 \\
\hline Assessing Use of Social Media in the Classroom & 3 \\
\hline Blogging & 2 \\
\hline Building a Network with Social Media & 2 \\
\hline Case Study Exploration: Social Media in the Real World & 1 \\
\hline Collaboration using Social Media & 4 \\
\hline Conceptual Framework for Emerging Technologies & 1 \\
\hline Copyright \& Privacy Issues & 2 \\
\hline Copyright and Privacy Issues: Case Studies in Social Media & 2 \\
\hline Creating a Social Media Account & 3 \\
\hline Curation & 1 \\
\hline Digital Citizenship & 8 \\
\hline Digital Communities and Social Influence: Using Social Media Professionally & 3 \\
\hline Digital Equity & 1 \\
\hline Digital Games & 1 \\
\hline Disruptive Innovation via Online Learning & 1 \\
\hline Evaluation of Web 2.0 Tools & 1 \\
\hline Facebook & 2 \\
\hline Google+ & 2 \\
\hline Harnessing the Power of the Crowd & 1 \\
\hline How Social Media Shapes Society & 1 \\
\hline How to Use Social Media in the Classroom & 2 \\
\hline Immersive Learning & 1 \\
\hline Infrastructure & 1 \\
\hline Instagram & 1 \\
\hline Licensing & 1 \\
\hline LinkedIn & 1 \\
\hline Mobile Learning & 1 \\
\hline Open Educational Resources & 2 \\
\hline Personal Learning Networks & 3 \\
\hline Personalization and Digital Teaching Platforms & 2 \\
\hline Pinterest & 2 \\
\hline Role of Cooperative Learning & 1 \\
\hline
\end{tabular}


Social Media Metrics 3

Social Networks and Social Good 1

Social Publishing $\quad 1$

Students as Designers and Makers 1

Technology Integration in Context 1

The Structure of Networks 1

Theoretical Backgrounds $\quad 4$

Twitter 4

Video, Images, and The New Classroom $\quad 1$

What is Social Media? $\quad 4$

YouTube 1

\section{RQ3: How is knowledge conveyed in the courses?}

The course content and knowledge conveyed in the courses was evaluated by assessing the required course readings. The analysis determined that the courses used textbooks and articles to serve as the sources of knowledge shared with the learners. The majority of the courses used articles (a total of 63) instead of textbooks. Some of these articles were non-peer-reviewed publications ( $n=38)$ such as columns, reviews, commentaries, and/or blog posts. In some instances, these articles were peer-reviewed publications $(n=25)$. Although the use and access to social media and social networking sites have gained greater popularity in the last decade, some of the journal articles listed under "required readings" for these courses are theories and concepts published in the 1970's, 1980's, and 1990's (see Table 3).

Table 3. Peer-Reviewed Journal Articles listed per Course

\section{Course Title $\quad$ Peer-Reviewed Journal Articles Listed in the Syllabi}

Social Networking: $\quad$ Granovetter, M. S. (1973). The strength of weak ties. American Journal of

Technology and Society Sociology, 78(6), 1360-1380. https://doi.org/10.1086/225469

Granovetter, M. (1983). The strength of weak ties: A network theory revisited. Sociological Theory, 1, 201-233. https://doi.org/10.2307/202051

Gilbert, E., \& Karahalios, K. (2009). Predicting tie strength with social media. Proceedings of the 27th International Conference on Human Factors in Computing Systems - CHI 09. https://doi.org/10.1145/1518701.1518736

Neustaedter, C., Tang, A., \& Tejinder, J. K. (2010). The role of community and groupware in geocache creation and maintenance. Proceedings of the 28th International Conference on Human Factors in Computing Systems CHI 10. https://doi.org/10.1145/1753326.1753590

Mergel, I. (2012). "Connecting to Congress": The use of Twitter by Members of Congress. Zeitschrift Für Politikberatung, 5(3), 108-114. https://doi.org/10.5771/1865-4789-2012-3-108 
Design of Online Collaborative

Introduction to Educational Technology

Foundations of Digital Learning
Yüzüncüyıl, K.S., \& Donaldson, J. A. (2016). How Web 2.0 technologies drive learning integration by using Twitter in the teaching process. Retrieved from https://members.aect.org/pdf/Proceedings/proceedings16/2016/16_24.pdf

Biasutti, M. (2017). A comparative analysis of forums and wikis as tools for online collaborative learning. Computers \& Education, 111, 158-171. https://doi.org/10.1016/j.compedu.2017.04.006

Warlick, D. (2009). Grow your personal learning network: New technologies can keep you connected and help you manage information overload. Learning \& Leading with Technology, 36(6), 12-16.

Keuler, A. (2012). Building a personal learning network for intellectual freedom: Join the conversation. Knowledge Quest, 41(2), 56-58.

Woods, B. (2013, November). Building your own PLN: Seeking new insights and ideas? Expand your personal learning network. TD Magazine. Retrieved from https://www.td.org/magazines/td-magazine/building-yourown-pln

Office of Educational Technology. (2016). National education technology plan: Reimagining the role of technology in education. U.S. Department of Education. Retrieved from: https://tech.ed.gov/netp/

Mahn, H. (1999). Vygotsky's methodological contribution to sociocultural theory. Remedial and Special Education, 20(6), 341-350. https://doi.org/10.1177/074193259902000607

Wilson, S. M., \& Peterson, P. L. (2006). Theories of learning and teaching: What do they mean for educators? Washington, DC: National Education Association.

Gee, J. P. (2009). Digital media and learning as an emerging field, Part I: How we got here. International Journal of Learning and Media, 1(2), 1323. https://doi.org/10.1162/ijlm.2009.0011

Koehler, M. J., Mishra, P., Bouck, E. C., DeSchryver, M., Kereluik, K., Shin, T. S., \& Wolf, L. G. (2011). Deep-play: Developing TPACK for 21st century teachers. International Journal of Learning Technology, 6(2), 146163.

Wargo, J. M. (2015). “Every selfie tells a story ...”: LGBTQ youth lifestreams and new media narratives as connective identity texts. New Media \& Society, 19(4), 560-578. https://doi.org/10.1177/1461444815612447

Garcia, A., Mirra, N., Morrell, E., Martinez, A., \& Scorza, D. (2015). The council of youth research: Critical literacy and civic agency in the digital age. Reading \& Writing Quarterly, 31(2), 151-167.

https://doi.org/10.1080/10573569.2014.962203 
Penuel, W. R., Horne, K. V., Digiacomo, D., \& Kirshner, B. (2016). A social practice theory of learning and becoming across contexts and time. Front Learning Research, 4(4), 30-38. https://doi.org/10.14786/flr.v4i4.205

Salomon, G. (2016). It's not just the tool but the educational rationale that counts. In E. Elstad (Ed.), Educational technology and polycontextual bridging (pp. 149-161). Springer Link. https://doi.org/10.1007/978-946300-645-3_8

Warschauer, M. (2016). Addressing the social envelope: Education and the digital divide. In C., Greenhow, J. Sonnevend, \& C. Agur (Eds.), Education and Social Media, (pp. 29-48). Oxford University Press. https://doi.org/10.7551/mitpress/9780262034470.003.0003

Five courses required a specific textbook as a reading (see Table 4). Unlike the peer review journal articles, the textbooks were all published within the last 10 years. A review of the titles suggested that most textbooks related to using educational technology strategies and tools to support learning. In fact, most of them focused on practical application of knowledge. In total, the syllabi listed 67 unique required readings including: non-peer reviewed publications, peerreviewed journal articles, and textbooks. None of the required readings were repeated amongst the different courses. It can be inferred, based on the list of required readings, that instructors use older publications to help guide the theories and concepts that are now applied to social media in teaching and learning and use the most updated readings to provide methods of actual application of the newly acquired knowledge in specific settings and platforms.

Table 4. Textbooks Listed per Course

\section{Course Name}

Design of Online Collaborative

Foundations of Digital Learning

Social Media

Social Networking: Technology and Society

Social Media \& Beyond

\section{Textbook}

Conrad, R., \& Donaldson, J. A. (2012). Continuing to engage the online learner: Activities and resources for creative instruction. San Francisco, CA: Jossey-Bass.

Selwyn, N. (2014). Distrusting educational technology: critical questions for changing times. New York, NY: Routledge.

Tuten, T., \& Solomon, M. (2014). Social media marketing (2nd ed.). Thousand Oaks, CA: Sage.

Barabasi, A. (2014). How everything is connected to everything else and what it means. New York, NY: Basic Books.

Joosten, T. (2012). Social media for educators: Strategies and best practices. San Francisco, CA: John Wiley \& Sons.

Anderson, P. (2012). Web 2.0 and beyond: Principles and technologies. Boca Raton, FL: CRC Press. 


\section{RQ4: How is learning assessed in the courses?}

During the analysis, the question "how is learning assessed?" was addressed by evaluating the required assignments listed for each course. To adequately analyze the assessment methods listed in the syllabi, the researchers first identified them in the documents. The assessment methods identified were grouped into specific "assessment themes." These themes were used to code all the topics listed (see Table 5).

The analysis of the assignments listed in the syllabi show that in these social media courses, there were a mix of traditional assessment methods such as: term/final papers, presentations, discussion forums, and quizzes. However, it was also palpable that non-traditional assessment methods were incorporated. Some of these non-traditional assessment methods focused on integrating social media as part of the assessment. For example, as listed in Table 5, some courses required learners to create a social media account (in a specific platform), become familiar with it, and create learning experiences incorporating a specific social media platform. In other instances, learners were asked to write blog posts and create resource libraries, both of these activities required using a specific social media platform as part of completing the assessment activity. Participation was also assessed differently, learners were required to share their thoughts, opinions, and response to questions in both class discussion format and through involvement in social media chats.

Table 5. Types of Assignments Listed in the Syllabi

Assignments and Examples

Paper

- The History of Twitter Paper

- Reflection Paper

Social Media Account Creation and Participation

- Create a Twitter account

- Create course-related networks

Participation

- Twitter Chat participation

- Participation in Webinars

Create a Lesson Plan

- Lesson plan using Pinterest

- Lesson plan using Twitter

Online Discussion Forums

5

- Discussion board

- Weekly Technology Post

Presentation

- Final Presentation

- Technology Presentation 
Quiz

- Open book quiz

- Blackboard quiz

Blog Post

- Blog entries

- Digital life post

Network Analysis

- Analysis of Network Project

Interview

- Interview a Parent and a student about their use of social media for personal and school use

Personalized Hashtag

- Create a personalized hashtag based on professional interest

Create a Resource Library

- Create a Diigo Resource Library

\section{Discussion}

Given the popularity and use of social media, it is imperative that its affordances, including those related to education, are better understood and disseminated. This investigation helped provide evidence about the course titles, learning objectives, and topics listed in the syllabi. It also provided critical data about the readings (peer-reviewed articles, non-peer reviewed, and books) and assessment methods used to convey knowledge and evaluate learning within these courses. The researchers conducted this investigation to inform future design and development of courses related to the use of social media for teaching and learning. Interest from instructors teaching in higher education, hoping to design courses related to social media, is likely to grow. Understanding how courses related to social media (with an education and learning context) are being taught now, can help other instructors plan new courses to meet the needs of their learners in the near future. Social media is likely to continue evolving. Having an idea of how social media for teaching and learning is been taught today, can better prepare us to consider topics that address the evolution of social media through the years. This takes into consideration both the historical and practical approach needed for adequate course design.

The findings of this investigation show that courses related to social media in education are just starting to be part of academic offerings. Hence, there is a great deal of variations on the course titles and the topics that are covered in these courses. However, across the different courses, the results do emphasize learning objectives that stress the practice and application of the knowledge acquired. Education majors enrolled in these courses are getting hands on experience on how to use social media for teaching and learning. This hands-on experiences includes: (a) ways in which different platforms can aid the learning process; and/or (b) how education majors themselves can leverage social media for their professional growth and knowledge. 
A thought-provoking finding from this investigation was that none of the assigned readings were recurrent across the different courses. Perhaps, this finding is related to the fact that there is a hefty number of publications related to social media in popular culture and social media in education. This large number of publications provide instructors with a sizable pool of readings from which to choose. Another noteworthy observation from the results is the use of older publications to help guide the concepts that are now applied to social media in teaching and learning. Perhaps these results illustrate that social media theories and knowledge have been around for a long period of time. What is new today are the mediums, applications, and platforms used to employ these theories and knowledge as well as how users consume these mediums.

Creativity was definitely showcased in the syllabi via the "required assignments" used to assess learning. Although some traditional methods of assessment were listed in the syllabi, based on the document analysis, instructors made a point of thinking creatively about ways to engage learners with social media while thinking and creating collaborative learning experiences for themselves and others. Based on the learning objectives listed and the alignment with the assessment methods used, it is clear that the instructors were also considering ways in which the learners can evaluate social media tools to gain an understanding of their functions and role in learning and instruction (if any).

Overall, the curriculum of the syllabi analyzed approach the learning experience as posteriori knowledge in which the learners are introduced to concepts and terms, given the opportunity to use social media, evaluate the mediums for use in education, and new knowledge is then applied. One aspect that is overlooked by the curriculum presented in the syllabi is deeper questioning of social media for its economic, cultural, and political aspects, which is critical in education. As stated by Ricaurte (2016),

innovation initiatives in educative institutions at any level limit themselves to reproducing the narratives and models designed by the agendas of technology corporations, and in a few occasions they consider original pedagogic proposals that contribute to a critical reflection about learning processes in relation to technology. (p. 3)

To fully expose learners to social media for teaching and learning, instructors should aim to consider topics that address and question issues, challenges, and negative aspects experienced by users in these online social settings.

One major limitation of this investigation is the number of syllabi analyzed. Every effort was made to collect and gather a representative sample of syllabi related to the topic of social media for teaching and learning. Yet, the data collection included fourteen usable course syllabi. Another limitation is the context of the syllabi analyzed. All of the syllabi included in the investigation are from institutions located within the U.S. territory. Future research should consider a wider search that could help reach institutions outside the U.S. territory. Additionally, future research with a larger sample of syllabi can consider illustrative questions that address context within the syllabi: is there a difference between public and private universities? Are some syllabi more conservative or more progressive? Is the curriculum designed on this topic very Westerncentered? Do the syllabi provide a critical view of social media or they take for granted that corporate social are good for collaboration?

\section{Conclusion}

As new trends and issues emerge in education, it is critical that we consider course offerings that allow us an opportunity to dissect and discuss them. It is also vital that these new courses in 
emerging topics are created with a systematic review that truly allows an understanding of the curriculum that best suits the topic. This syllabus analysis is the first attempt to investigate the characteristics of the curriculum of courses related to social media with an education and learning context. The results of this investigation provide a beneficial framework and foundation of the curriculum developed so far. As previously mentioned, social media use continues to grow. We will continue to see ramifications of the use and adoption of social media in many different areas, including the teaching and learning sector. As instructors prepare themselves to educate future learners on the benefits and challenges of social media for learning, is it vital to look at our syllabi and allow them to tell the story of how we teach others about social media.

\section{Acknowledgements}

This work was supported by The University of Tampa under a Research Innovation and Scholarly Excellence (RISE) Grant [GR0038]. This paper was accepted and presented the Association for Educational Communications and Technology (AECT) International Convention.

\section{References}

Allen, K., \& Nelson, D. (2013). A case study on integrating social media in an online graduate youth development course. Journal of Online Learning \& Teaching, 9(4), 566-574.

Alzouebi, K., \& Isakovic, A. A. (2014). Exploring the learner perspective of social media in higher education in the United Arab Emirates. Global Education Journal, 2014(2), 13-31.

Atkins, B., Koroluk, J., \& Stranach, M. (2017). Canadian teaching and learning centres on Facebook and Twitter: An exploration through social media. TechTrends, 61(3), 253-262. https://doi.org/10.1007/s11528-016-0144-2

Becker, R., \& Bishop, P. (2016). "Think bigger about science": Using Twitter for learning in the middle grades. Middle School Journal, 47(3), 4-16. https://doi.org/10.1080/00940771.2016.1135097

Benson, V., \& Morgan, S. (2013). Social Higher Education: How Effective is it? Proceedings of the International Conference on e-Learning, 45-51.

Bers, T., Davis, B., \& Taylor, B. (2000). The use of syllabi in assessments: Unobtrusive indicators and tools for faculty development. Assessment Update, 12(3), 4-7.

Bista, K. (2015). Is Twitter an effective pedagogical tool in higher education? Perspectives of education graduate students. Journal of the Scholarship of Teaching \& Learning, 15(2), 83-102. https://doi.org/10.14434/josotl.v15i2.12825

Brocato, E. D., White, N. J., Bartkus, K., \& Brocato, A. A. (2015). Social media and marketing education: A review of current practices in curriculum development. Journal of Marketing Education, 37(2), 76-87. https://doi.org/10.1177/0273475315588110

Brookfield, S. D. (2015). Teaching students to think critically about social media. New Directions for Teaching and Learning, 2015(144), 47-56. https://doi.org/10.1002/tl.20162

Cañadas, M. C., Gómez, P., \& Rico, L. (2013). Structure of primary mathematics teacher education programs in Spain. International Journal of Science and Mathematics Education, 11(4), 879-894. https://doi.org/10.1007/s10763-013-9422-z

Dabbagh, N., \& Kitsantas, A. (2012). Personal learning environments, social media, and self-regulated learning: A natural formula for connecting formal and informal learning. The Internet and Higher Education, 15(1), 3-8. https://doi.org/10.1016/j.iheduc.2011.06.002 
DiVall, M. V., \& Kirwin, J. L. (2012). Using Facebook to facilitate course-related discussion between students and faculty members. American Journal of Pharmaceutical Education, 76(2), 32. https://doi.org/10.5688/ajpe76232

Evans, C. (2014). Twitter for teaching: Can social media be used to enhance the process of learning? British Journal of Educational Technology, 45(5), 902-915. https://doi.org/10.1111/bjet.12099

Faulds, D. J., \& Mangold, W. G. (2014). Developing a social media and marketing course. Marketing Education Review, 24(2), 127-144. https://doi.org/10.2753/MER1052-8008240204

Gomes, A. W., Butera, G., Chretien, K. C., \& Kind, T. (2017). The development and impact of a social media and professionalism course for medical students. Teaching and Learning in Medicine, 29(3), 296-303. https://doi.org/10.1080/10401334.2016.1275971

Greenhalgh, S. P., \& Koehler, M. J. (2017). 28 Days Later: Twitter hashtags as "Just in Time" teacher professional development. TechTrends, 61(3), 273-281. https://doi.org/10.1007/s11528-016-0142-4

Greenhalgh, S. P., Staudt Willet, K. B., Rosenberg, J. M., \& Koehler, M. J. (2018). Tweet, and we shall find: Using digital methods to locate participants in educational hashtags. TechTrends, 62(5), 501508. https://doi.org/10.1007/s11528-018-0313-6

Guidry, K. R., \& Pasquini, L. A. (2013). Twitter chat as a non-formal learning tool: A case study using \#sachat. In H. H. Yang \& S. Wang (Eds.), Cases on formal and Informal e-Learning environments: Opportunities and practices. IGI Global. https://doi.org/10.4018/978-1-4666-1930-2.ch019

Hemsley, J., Jacobson, J., Gruzd, A., \& Mai, P. (2018). Social media for social good or evil: An introduction. Social Media + Society, 4(3). https://doi.org/10.1177/2056305118786719

Ji-Yeon, C., Wooyeon, K., \& Heewon, L. (2013). Identification of essential English productive skills for English-medium instruction courses: A syllabus analysis. English Teaching, 68(3), 159-186. https://doi.org/10.15858/engtea.68.3.201309.159

Kimmons, R., \& Veletsianos, G. (2016). Education scholars' evolving uses of Twitter as a conference backchannel and social commentary platform. British Journal of Educational Technology, 47(3), 445464. https://doi.org10.1111/bjet.12428

Krutka, D. G., \& Carpenter, J. P. (2017). DIGITAL CITIZENSHIP in the curriculum: Educators can support strong visions of citizenship by teaching with and about social media. Educational Leadership, 75(3), 50-55.

Lin, M.-F., Hoffman, E., \& Borengasser, C. (2013). Is social media too social for class? A case study of twitter use. TechTrends: Linking Research \& Practice to Improve Learning, 57(2), 39-45. https://doi.org/10.1007/s11528-013-0644-2

Luo, T., Sickel, J., \& Cheng, L. (2017). Preservice teachers' participation and perceptions of Twitter live chats as personal learning networks. TechTrends, 61(3), 226-235. https://doi.org/10.1007/s11528016-0137-1

Manca, S., \& Ranieri, M. (2017). Implications of social network sites for teaching and learning. Where we are and where we want to go. Education and Information Technologies, 22(2), 605-622. https://doi.org/10.1007/s10639-015-9429-X

Manca, S., \& Ranieri, M. (2016). Facebook and the others. Potentials and obstacles of social media for teaching in higher education. Computers \& Education, 95, 216-230.

Myers, L. H., Jeffery, A. D., Nimmagadda, H., Werthman, J. A., \& Jordan, K. (2015). Building a community of scholars: One cohort's experience in an online and distance education doctor of philosophy program. Journal of Nursing Education, 54(11), 650-654. https://doi.org/10.3928_01484834-20151016-07

Pham, A. V. (2014). Navigating social networking and social media in school psychology: Ethical and professional considerations in training programs. Psychology in the Schools, 51(7), 767-778. https://doi.org/10.1002/pits. 21774 
Ricaurte, P. (2016). Pedagogies for the open knowledge society. International Journal of Educational Technology in Higher Education, 13(1), 1-10.

Romero-Hall, E. (2017). Posting, sharing, networking, and connecting: Use of social media content by graduate students. TechTrends, 61(6), 580-588. https://doi.org/10.1007/s11528-017-0173-5

Spallek, H., Turner, S. P., Donate-Bartfield, E., Chambers, D., McAndrew, M., Zarkowski, P., \& Karimbux, N. (2015). Social media in the dental school environment, Part B: Curricular considerations. Journal of Dental Education, 79(10), 1153.

Stanny, C., Gonzalez, M., \& McGowan, B. (2015). Assessing the culture of teaching and learning through a syllabus review. Assessment \& Evaluation in Higher Education, 40(7), 898-913. https://doi.org/10.1080/02602938.2014.956684

Tess, P. A. (2013). The role of social media in higher education classes (real and virtual)-A literature review. Computers in Human Behavior, 29(5), A60-A68.

Tuten, T., \& Marks, M. (2012). The adoption of social media as educational technology among marketing educators. Marketing Education Review, 22(3), 201-214. https://doi.org/10.2753/MER1052$\underline{8008220301}$

Veletsianos, G., \& Stewart, B. (2016). Discreet openness: scholars' selective and intentional selfdisclosures online. Social Media + Society, 2(3), 2056305116664222.

https://doi.org/10.1177/2056305116664222

Villar, F., Giuliani, M. F., Serrat, R., Curcio, C. L., Lopes, A., de la Martinez Maldonado, M., \& de Cassia Oliveira, R. (2017). Gerontological training programs offered by Latin American universities: Number, characteristics, and disciplinary contents. Educational Gerontology, 43(5), 238-247. https://doi.org/10.1080/07481187.2017.1281032

Xi, Z., Hui, C., de Pablos, P. O., Lytras, M. D., \& Yongqiang, S. (2016). Coordinated implicitly? An empirical study on the role of social media in collaborative learning. International Review of Research in Open \& Distance Learning, 17(6), 121-144.

\section{JL}

